\title{
Turbulences in Boundary Layer of Flat Plates
}

\author{
Alexander Tesar \\ Institute of Construction and Architecture, Slovak Academy of Sciences, Bratislava \\ e-mail: alexander.tesar@gmail.com
}

\begin{abstract}
The aeroelastic assessment of turbulences appearing in boundary layer of flat plates tested in the wind tunnel is treated in present paper. The approach suggested takes into account multiple functions in the analysis of flat plates subjected to laminar and turbulent wind forcing. Analysis and experimental assessments in the aerodynamic tunnel are presented. Some results obtained are discussed.
\end{abstract}

Key words: aerodynamic tunnel, aeroelasticity, boundary layer, flat plate, turbulent wind motion, wave propagation

\section{Introduction}

The topic of present paper is the assessment of turbulences around the flat plates subjected to laminar and turbulent wind forcing (see Fig. 1). The problem was previously dealt with in structural and bridge engineering in references [1 - 9].

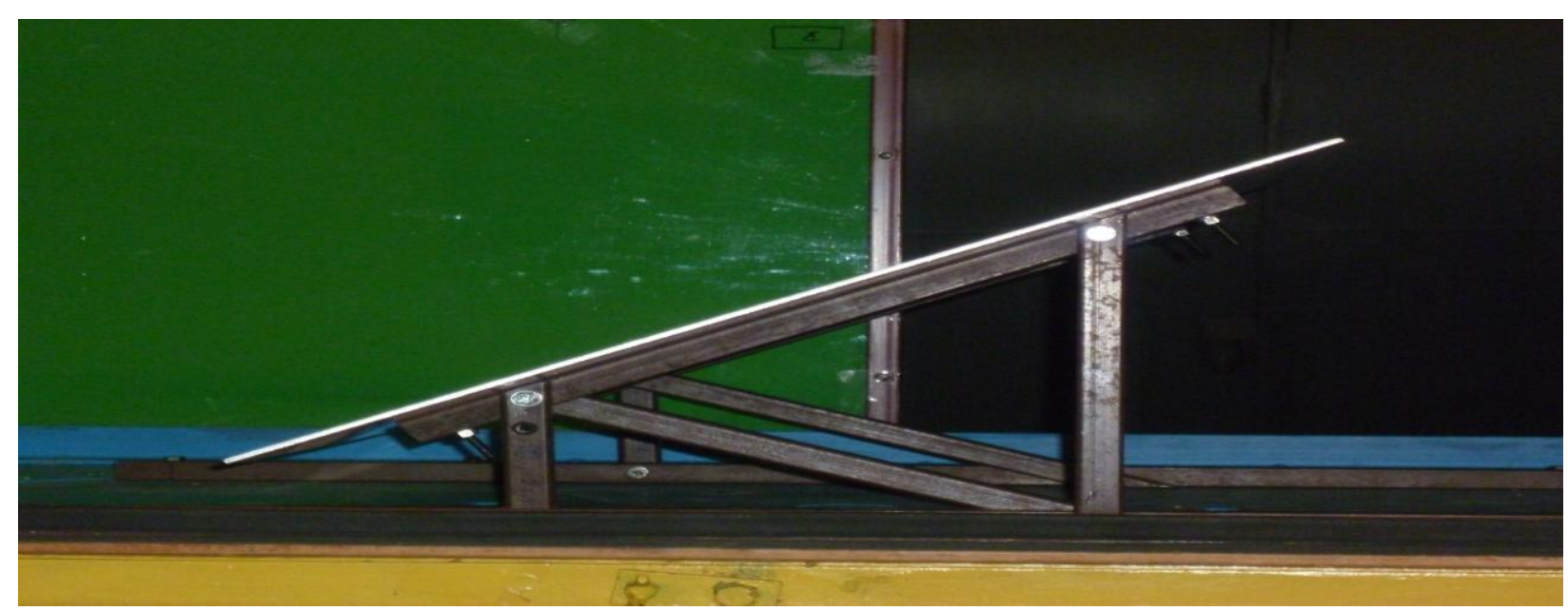

Figure 1: Side view of the plate studied in wind tunnel 
Flat plates are to be designed in accordance with valid standards and their aeroelastic assessment is required due to the recommendations of the EUROCODE 1, Loads on Structures, Part 1.4, General Loads, Wind Loads ([10]). The primary objective of this work was the determination of the coupling, interaction and separation of the effects of various modes of air oscillation as they may exist in wind turbulence and may have a bearing on ultimate response and noise generation of the flat plates studied. Identified are the wave-type solutions of the flow equations corresponding to vortical, entropy and acoustic modes of propagation. In scope of the wind action there occur turbulent air flows on edges of the flat plates with increase of wind speeds and pressures. Regarding the variability of configurations of plates there appear laminar and turbulent air flows measurable only in the wind tunnel. The measurement submits the data for the analysis of the problem.

\section{Mechanics of turbulent motion}

All turbulences in the wind forcing are considered as a special family of motions from one space region into another one. Their updated configuration is specified by location of the air displacements in space and time. The variations of configurations are continuous and during deformation there appear no new boundary conditions. Each new configuration is related to a reference position stated. When taking into account the Cartesian coordinates $x, y, z$ and corresponding displacements $u, v, w$, the Green strain tensor is given by

$$
\begin{gathered}
E_{x x}=\partial u_{x} / \partial x+\left[\left(\partial u_{x} / \partial x\right)^{2}+\left(\partial u_{y} / \partial y\right)^{2}+\left(\partial u_{z} / \partial z\right)^{2}\right] / 2, \\
E_{x y}=\left[\left(\partial u_{y} / \partial x\right)+\left(\partial u_{x} / \partial y\right)+\left(\partial u_{x} / \partial x\right)\left(\partial u_{x} / \partial y\right)+\left(\partial u_{y} / \partial x\right)\left(\partial u_{y} / \partial y\right)+\left(\partial u_{z} / \partial x\right)\left(\partial u_{z} / \partial y\right)\right] / 2, \\
\ldots, \text { etc. }
\end{gathered}
$$

In order to set up the constitutive equations, the stress tensor with the same reference is needed. The second Piola-Kirchhoff stress tensor $S_{i j}$ has the properties required and the generalized equation of the air flow is given by

$$
S_{i j}=g\left(E_{i j}\right)
$$

with $\mathrm{g}$ as function of the Green strain tensor $E_{i j}$.

When analyzing the air flow with volume, surface area and density, $B, S$ and $\rho_{o}$, respectively, the volume forces of the mass unit are given by $F_{o, i}$ and strains by $T_{i}$. The flow in equilibrium is submitted to a virtual displacement $\delta u_{i}$ being consistent with initial conditions assumed. The equilibrium of the virtual work is given by

with substitution

$$
\int S_{i j} \delta E_{i j} d B-\int T_{i} \delta u_{i} d S-\int P_{i} \delta u_{i} d B=0
$$

$$
P_{i}=\rho_{o} F_{o, i}
$$

Equation (4) specifies the stationary value of the potential energy in all deformations $u_{i}$. The incremental equivalent of corresponding variation principle is given by 


$$
\begin{aligned}
& \int S_{i j}{ }^{(1)} \delta E_{i j}{ }^{(1)} d B-\int T_{i}^{(1)} d u_{i}{ }^{(1)} d S-\int P_{i}{ }^{(1)} \delta u_{i}{ }^{(1)} d B=0, \\
& \int S_{i j}{ }^{(2)} \delta E_{i j}{ }^{(2)} d B-\int T_{i}^{(2)} d u_{i}{ }^{(2)} d S-\int P_{i}{ }^{(2)} \delta u_{i}{ }^{(2)} d B=0,
\end{aligned}
$$

with superscripts (1) and (2) for neighboring configurations studied. The strains and volume forces have the same reference configuration and there holds

$$
\begin{aligned}
& \Delta T_{i}=T_{i}^{(2)}-T_{i}^{(1)} \\
& \Delta P_{i}=P_{i}^{(2)}-P_{i}^{(1)} .
\end{aligned} .
$$

The variations of both deformation fields are the same

$$
\delta u_{i}=\delta u_{i}^{(1)}=\delta u_{i}^{(2)}
$$

The incremental virtual work equation is given by Eqs. (6) and (7)

$$
\int\left(S_{i j}{ }^{(2)} \delta E_{i j}{ }^{(2)}-S_{i j}^{(1)} \delta E_{i j}{ }^{(1)}\right) d B-\int \Delta T_{i} \delta u_{i} d S-\int \Delta P_{i} \delta u_{i} d B=0,
$$

when taking into account the virtual variations of both configurations studied. Equation (11) specifies the configuration (2) from known configuration (1) and known load increments. When the work made by mass and damping forces on virtual displacements $\delta u_{i}$ is added to Eq. (4), the principle of virtual works for the problem studied is given by

$$
\int S_{i j} \delta E_{i j} d B+\int \rho u_{i} \delta u_{i} d B+\int C_{i} u_{i} \delta u_{i} d B-\int T_{i} \delta u_{i} d S-\int P_{i} \delta u_{i} d B=0
$$

where $\rho$ and $C$ are mass and damping terms.

The turbulence in the air flow is described by instantaneous wind speed as a function of space and time with mean and fluctuation components given by

$$
\begin{gathered}
u(x, y, z, t)=U(x, y, z)+u^{\prime}(x, y, z), \\
v(x, y, z, t)=V(x, y, z)+v^{\prime}(x, y, z), \\
w(x, y, z, t)=W(x, y, z)+w^{\prime}(x, y, z) .
\end{gathered}
$$

The mean values of projections $U, V, W$ are the result of averaging in a certain interval of time the wind speed and the fluctuating components.

The turbulence scales of the instantaneous wind speed are the measure of representative dimensions of vortices induced by turbulences inside air flow. They describe the turbulences which ,wrap“ the flat plate in a certain time.

The assessment of turbulence motion starts with specification of correlation functions of fluctuating components which may be longitudinal, transversal and vertical. In general, the characteristics of the air flow are well defined if the correlation functions are specified for the mean streamwise components longitudinally and transversally. The correlation in time is specified by formulae 


$$
\begin{gathered}
\left.\rho_{u(i) u(j)}(\tau)=R_{u(i) u(j)}(\tau) /\left(\sqrt{ }\left(u^{\prime}\right)^{2}(t)\right) \cdot\left(\sqrt{ }\left(u^{\prime}\right)^{2}(t+\tau)\right)\right], \\
R_{u(i) u(j)}(\tau)=u_{i}(t) \cdot u_{j}(t+\tau)=\lim _{T \rightarrow \infty} 1 / T \int\left[u_{i}(t) \cdot u_{j}(t+\tau)\right] d t .
\end{gathered}
$$

Eq. (17) represents the covariance function of the process $u(t)$ being determined by measuring in two different points in space at the difference of time $\tau$ (see Refs. [13], [14] and [15]).

According to Taylor's hypothesis ([13] the inter-correlation between any of the fluctuating parts, discarding the wind instantaneous speed measured in two points being separated by distance $\Delta x$ in direction of the wind flow, is equal with the auto-covariance determined for the period studied. The inter-correlation functions give information concerning the dimensions of the turbulences in direction of the wind action. The existence of the mean values of the wind speed inside of turbulent flow is given by the reality that in a certain point $i$ the turbulence has a certain periodicity in time. After a certain period the phenomenon repeats itself in space. These two idioms specify the turbulence scales in time and space. The turbulence scales define the frequency of gusts in the wind action. The integral length scales correspond to spatial nature of the wind action specifying the longitudinal, lateral and vertical scales given by

$$
\begin{aligned}
L_{x} & =\int \rho_{u^{\prime}(i) u^{\prime}(j)}(\Delta x, 0,0) d(\Delta x), \\
L_{y} & =\int \rho_{u^{\prime}(i) u^{\prime}(j)}(0, \Delta y, 0) d(\Delta y), \\
L_{z} & =\int \rho_{u^{\prime}(i) u^{\prime}(j)}(0,0, \Delta z) d(\Delta z),
\end{aligned}
$$

with integration from 0 until $\infty$. The most important of these three is the longitudinal scale, the other two being practically its derivatives. The integral time scale of the turbulence is defined by

$$
\Lambda_{T}=\int \rho_{u^{\prime}(i) u^{\prime}(j)}(\tau) d \tau
$$

According to above Taylor's hypothesis, the longitudinal scale of turbulence may be specified by the integral time scale and by the mean wind speed value $\mathrm{V}$ in the streamwise direction by

$$
L_{x}=V \cdot \Lambda_{T}
$$

The studies for determination of the turbulence scale, both at natural scale and in laboratory, have produced the empirical Davenport's formula

$$
\Lambda_{T}=0.084 \mathrm{~L} / \mathrm{V},
$$

given in sec, where $L$ is the longitudinal scale of the in-wind speed and $V$ is the mean wind speed.

In EN 1991-1-4 the integral length scales in wind direction depend on the mean wind velocity and height $\mathrm{z}$, in accordance with Ref. [15].

The incorporation of above forcing into the behavior of the flat plate is specified by wave propagation with corresponding interactions of laminar and turbulent air flows. The waves 
initiated are specified by the spectral evolution describing the occurrence of wind turbulences. The spectral evolution is based on following definitions:

1. Each stationary function $x(t)$ is given in integral form

$$
x(t)=\int e^{i \omega t} d A(\omega)
$$

with symbol $A(\omega)$ for orthogonal complex process studied.

2. Linear transformation $y(t)$ of the function $x(t)$ in Eq. (24) is given by

$$
y(t)=\int H(i \omega) e^{i \omega t} d A(\omega),
$$

with $H(\omega)$ as corresponding admittance function.

3. Spectral densities of functions $x(t)$ and $y(t)$ are connected by

$$
S_{y}(\omega) / S_{x}(\omega)=/\left.H(i \omega)\right|^{2} .
$$

Turbulent air flow is defined by a wave number $r_{i}(\omega)$, with longitudinal and shear waves. Stationary waves are emitted with complex amplitude $F\left(\omega, z_{o}\right)$, e.g., $z=z_{o}$. The wave superposition is given by

$$
w_{i}(t, z)=\int e^{-i \omega t} e^{i r(\omega z)} d F\left(\omega, z_{o}\right)
$$

For wave interactions in the turbulences the forcing spectrum is given by $S(\omega, 0)$ as function of the response $H(\omega, 0)$ to the wind action.

\section{Flat plate response}

The analysis of ultimate behavior of flat plates subjected to above forcing is based on the adoption of the Lagrange formulation of motion. The reference state of the plate is incrementally updated during deformation process. The new reference configuration is established at each degree of updated deformation curve in ultimate response of the plate. Incremental form of the equation of motion is given by the analysis of aeroelastic equilibrium of two configurations at time step $\Delta t$ apart. The increments of laminar and turbulent forcing balance the aeroelastic equilibrium in time $t+\Delta t$ by

$$
M_{t} \Delta a_{t}+C_{t} \Delta v_{t}+K_{t} \Delta u_{t}=R_{t+\Delta t}-\left(V_{t}^{I}+V_{t}^{D}+V_{t}^{S}\right)
$$

with inertia forces $V_{t}^{I}=M_{t} a_{t}$, damping forces $V_{t}^{D}=C_{t} v_{t}$, stiffness forces $V_{t}^{S}=K_{t} u_{t}$ and with accelerations, velocities and displacements $a_{t}, v_{t}, u_{t}$, respectively. The vectors of accelerations and velocities are given by time derivatives of deformation vector $\mathrm{u}_{\mathrm{t}}$. The mass, damping and stiffness matrices $M_{t}, C_{t}$ and $K_{t}$, respectively, are constructed of element matrices of the plate model studied. The subscript $t$ denotes the actual time and $R$ is the vector of laminar and turbulent forcing. If the plate is in equilibrium in time $t$, then right side of Eq. (28) is identical 
with the increments of forcing in time step $\Delta t$. The increments in displacements, velocities and accelerations are given by increments of forcing and by the matrices of physical properties of the plate studied. If such matrices are variable in time then the validity of Eq. (28) is satisfied only approximately. The approximation error is given by

$$
\Delta V_{t+\Delta t}=R_{t+\Delta t}-\left(V_{t+\Delta t}^{I}+V_{t+\Delta t}^{D}+V_{t+\Delta t}\right)
$$

as a measure of solution accuracy when adopting Eq. (28). Governing incremental equation of motion is then given by modification of Eq. (28) as

$$
M_{t} \Delta a_{t}+C_{t} \Delta v_{t}+P_{t} \Delta u_{t}=\Delta R_{t}
$$

where $P_{t} \Delta u_{t}$ is the vector of nonlinear forces. The pseudo-force method ([7]) adopted is given by

$$
P_{t} \Delta u_{t}=K_{t} \Delta u_{t}+N_{t} \Delta u_{t}-\Delta V_{t+\Delta t}
$$

where $N_{t} \Delta u_{t}$ is the vector of aerodynamic nonlinear forces (pseudo-forces) and $\Delta V_{t+\Delta t}$ is above approximation error. When adopting the pseudo-force technique, the member $P_{t} \Delta u_{t}$ is located on the right side of Eq. (30) and the vector of nonlinear forces is applied as the vector of pseudo-forces. In each time step the approximation $N_{t} \Delta u_{t}$ is calculated and the iterations run until the term $\Delta V_{t+\Delta t}$ is comparable with tolerance norm adopted. The approximation $N_{t}$ $\Delta u_{t}$ in first iteration step is given by

$$
N_{t} \Delta u_{t}=(1+\beta) N_{t-\Delta t} \Delta u_{t-\Delta t}-\beta N_{t-2 \Delta t} \Delta u_{t-2 \Delta t},
$$

with $\beta$ as extrapolation parameter in scope from 0 until 1.

\section{Experiment}

The testing was made with the model set-up of flat plate in scale 1:10, developed on the basis of the model similarity with actual structure ([16]). The aerodynamic testing was made in the wind tunnel of the Institute of Construction and Architecture of Slovak Academy of Sciences in Bratislava, Slovakia. Assumed was the type of atmospheric boundary layer suitable for terrain of category II. For testing was used the section with cross-sectional dimensions $1200 \mathrm{x}$ $1200 \mathrm{~mm}$ and length $6000 \mathrm{~mm}$. Maximal wind velocity obtained was $51 \mathrm{~m} / \mathrm{sec}$. The details of experiment, the model similarity with atmospheric boundary layer simulated in the wind tunnel, the model scale of the model and of the wind speed considering the wind direction and intensity of turbulences, etc., are summed up in Ref. [16]. The model of flat plate was made with dimensions $1000 \times 300 \mathrm{~mm}$ and width $4 \mathrm{~mm}$. The plate was supported by steel supports Jäckl 20/20/2 and anchored into the floor of the tunnel. The view of experimental set-up in the tunnel is in Fig. 1. In case of the wind forcing there appear the turbulences on upper and lower edges of the plate accompanied by wind gusts and local changes of the wind velocity. Required was therefore the specification of actual wind velocities appearing on all edges of the plate at various wind speeds in aerodynamic tunnel. The speed variations in the wind flow were given by aerodynamic coefficient $\alpha$ 
Plex. Panel Mer 17 April 2008 Mer1 150 Wind Pressure MaxVel $38 \mathrm{~m} / \mathrm{s}$
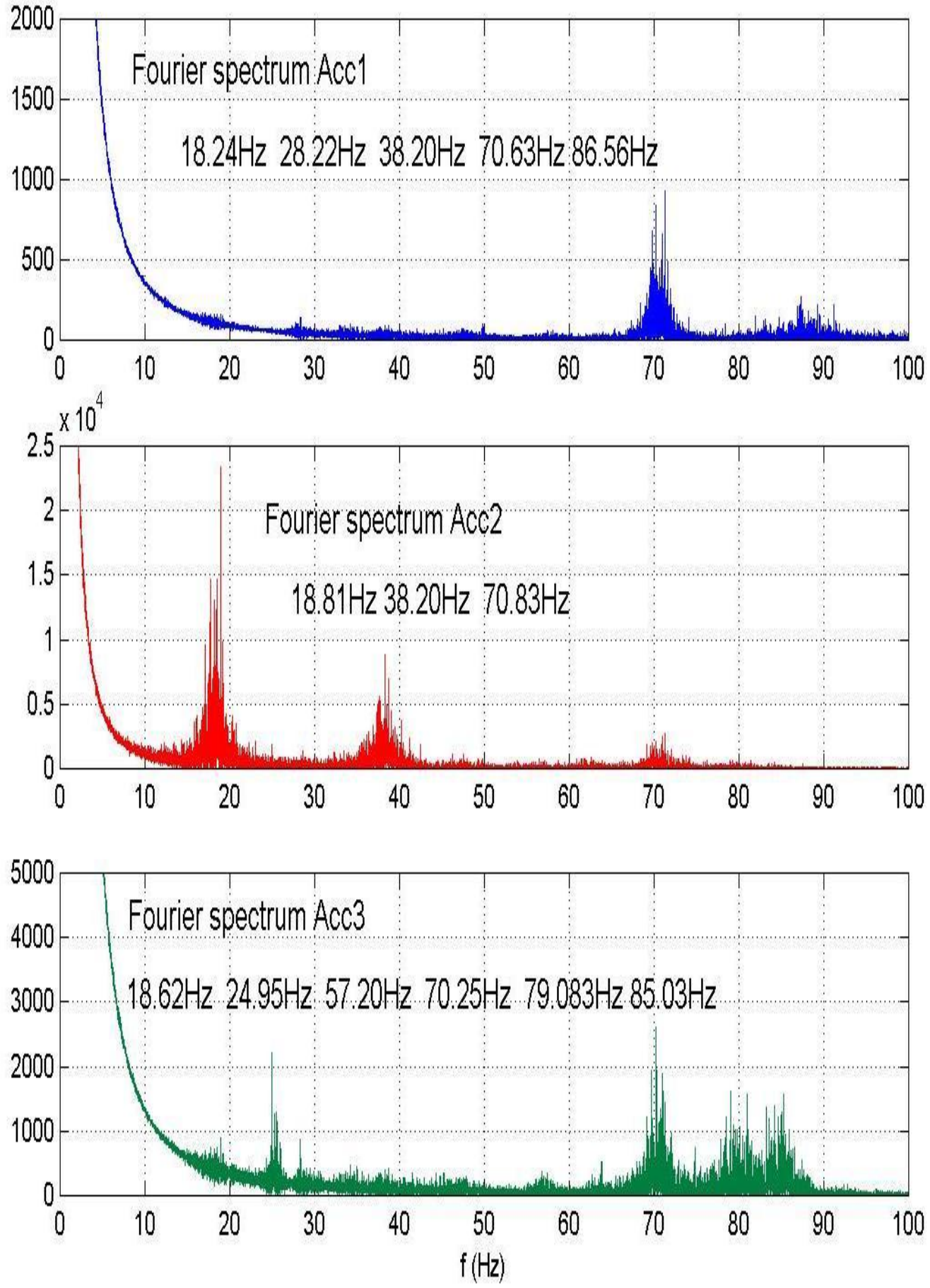

Figure 2: Fourier spectra of accelerations A1, A2, A3 (upper, lower and side edges of plate) at angle $+90^{\circ}$ (wind speed $38 \mathrm{~m} / \mathrm{sec}$ )

$$
\alpha=v_{\text {lod }} v_{\text {ave }},
$$


with $v_{l o c}$ as local velocity of turbulent wind flow measured on the edge of the plate and with $v_{\text {ave }}$ as averaged velocity of laminar wind flow in aerodynamic tunnel. The value $v_{\text {ave }}$ corresponds to the standard wind velocity in given territory and was used for the design of all structural elements of the flat plate studied. The coefficient $\alpha$ specifies the increase of the wind velocity on the edges of the plate. One of the goals of experimental testing was therefore the specification of the aerodynamic coefficient $\alpha$ on all edges of the plate.

The values of coefficient $\alpha$ were adopted for specification of resulting stress and deformation states in the plate.

The testing was made for:

a) model in horizontal attitude $\left(0^{\circ}\right)$ and located perpendicularly to the direction of wind flow - the assessment of the shear wind along the plate (Fig. 1),

b) model in horizontal attitude and turned $-180^{\circ}$ compared with wind flow - the assessment of the air sucking on the plate.

c) model in horizontal attitude and turned $+90^{\circ}$ compared with wind flow - the assessment of wind pressure on the plate.

In Fig. 2 are typical Fourier spectra of accelerations A1, A2, A3 (upper, lower and side edges of plate) at angle $+90^{\circ}$ and by the wind speed $38 \mathrm{~m} / \mathrm{sec}$.

In accordance with the measurements made in critical points and with results summed up in Table 1 was stated, that response of the plate is dominated by deformations with turbulent components of pressure and sucking of wind which are irregularly distributed along the surface of the plate. Turbulent wind flows initiate the ultimate response of the plate. Some obtained values of aerodynamic coefficient $\alpha$ are summed up in Table 1.

The Table 1 contains the wind speeds on the edges of plate, specified in scope of measurements at various wind speeds. There are summed up automatically established wind speeds $10-50 \mathrm{~m} / \mathrm{sec}$ in aerodynamic tunnel, averaged actual wind speeds $v_{\text {ave }}$ in the tunnel as well as local wind speeds $v_{l o c}$ on all edges of the plate.

In Table 1 are also given the aerodynamic coefficients $\alpha=v_{l o c} / v_{\text {ave }}$ on all edges of the plate. Presented is also the comparison of measured and calculated values $\alpha$.

Average increase of speeds and pressures of wind flows on the upper, lower and side edges of the plate are given by aerodynamic coefficients $\alpha=1.4255,1.6532$ and 1.4080 , respectively.

Average increase of the wind pressure on the plate due to change of the wind direction and due to turbulences appearing is given for wind sucking by coefficient -1.65 and for the wind pressure by coefficient 1.43 of standard values valid for the face action of the wind on the model.

Due to appearance of the wind gusts was initiated the ultimate response of the model. There appeared combined axial and shear amplitudes of vibration parallel with the plane of the plate. 
Table 1: Some results of measurements and comparison with calculated vales $\alpha$ (in brackets)

\begin{tabular}{|c|c|c|c|c|c|c|c|c|c|}
\hline $\begin{array}{c}\text { Wind } \\
\text { speed } \\
{[\mathrm{m} / \mathrm{sec}]}\end{array}$ & $\begin{array}{c}\text { Measu- } \\
\text { rement } \\
\text { Nr. } 7 \\
\mathrm{~V}_{\text {loc }} \\
{[\mathrm{m} / \mathrm{sec}]}\end{array}$ & $\begin{array}{c}\text { Measu- } \\
\text { rement } \\
\text { Nr. } 7 \\
\mathrm{~V}_{\text {ave }} \\
{[\mathrm{m} / \mathrm{sec}]}\end{array}$ & $\begin{array}{c}\text { Measu- } \\
\text { rement } \\
\text { Nr. } 7 \\
\alpha=\mathrm{v}_{\text {loc }} / \mathrm{v}_{\text {ave }}\end{array}$ & $\begin{array}{c}\text { Measu- } \\
\text { rement } \\
\mathrm{Nr} .8 \\
\mathrm{v}_{\text {loc }} \\
{[\mathrm{m} / \mathrm{sec}]}\end{array}$ & $\begin{array}{c}\text { Measu- } \\
\text { rement } \\
\text { Nr. } 8 \\
\mathrm{~V}_{\text {ave }} \\
{[\mathrm{m} / \mathrm{sec}]}\end{array}$ & $\begin{array}{c}\text { Measu- } \\
\text { rement } \\
\text { Nr. } 8 \\
\alpha=\mathrm{v}_{\text {loc }} / \mathrm{v}_{\text {ave }}\end{array}$ & $\begin{array}{c}\text { Measu- } \\
\text { rement } \\
\mathrm{Nr} .9 \\
\mathrm{v}_{\mathrm{loc}} \\
{[\mathrm{m} / \mathrm{sec}]}\end{array}$ & $\begin{array}{c}\text { Measu- } \\
\text { rement } \\
\mathrm{Nr} .9 \\
\mathrm{~V}_{\text {ave }} \\
{[\mathrm{m} / \mathrm{sec}]}\end{array}$ & $\begin{array}{c}\text { Measu- } \\
\text { rement } \\
\text { Nr. } 9 \\
\alpha=\mathrm{v}_{\text {loc }} / \mathrm{v}_{\text {ave }}\end{array}$ \\
\hline 10 & 13.7 & 10.1 & $\begin{array}{l}1.3564 \\
(1.3762)\end{array}$ & 17.8 & 10.1 & $\begin{array}{l}1.7623 \\
(1.8142)\end{array}$ & 14.3 & 10.1 & $\begin{array}{l}1.4158 \\
(1.4833)\end{array}$ \\
\hline 20 & 26.8 & 20.2 & $\begin{array}{l}1.3267 \\
(1.3341)\end{array}$ & 36.6 & 20.2 & $\begin{array}{l}1.8119 \\
(1.8231)\end{array}$ & 28.7 & 20.2 & $\begin{array}{l}1.4208 \\
(1.4471)\end{array}$ \\
\hline 30 & 38.9 & 30.1 & $\begin{array}{l}1.2923 \\
(1.3026)\end{array}$ & 49.9 & 30.1 & $\begin{array}{l}1.6578 \\
(1.8452)\end{array}$ & 40.4 & 30.1 & $\begin{array}{l}1.3422 \\
(1.3610)\end{array}$ \\
\hline 40 & 52.4 & 40.1 & $\begin{array}{l}1.3067 \\
(1.3161)\end{array}$ & 60.7 & 40.1 & $\begin{array}{l}1.5137 \\
(1.5338)\end{array}$ & 52.6 & 40.1 & $\begin{array}{l}1.3117 \\
(1.3275)\end{array}$ \\
\hline 50 & 66.2 & 50.2 & $\begin{array}{l}1.3187 \\
(1.3228)\end{array}$ & 76.8 & 50.2 & $\begin{array}{l}1.5299 \\
(1.5730)\end{array}$ & 67.7 & 50.2 & $\begin{array}{l}1.3488 \\
(1.3722)\end{array}$ \\
\hline
\end{tabular}

\section{Conclusion}

On the basis of the evaluation of the results obtained has been found, that ultimate displacements and stress states appear in boundary regions of the plate, where the wind flows have distinctly turbulent character.

\section{Acknowledgements}

Author is obliged to Slovak scientific agencies VEGA and APVV for supporting present research.

\section{References}

[1] Bleich, F. (1950). The mathematical theory of vibration in suspension bridges. Washington: United States Government Printing Office.

[2] Selberg, A. (1961). Oscillation and aerodynamic stability of suspension bridges. Acta P. 308, Ci. 3.

[3] Theodorsen, T. (1935). General theory of aerodynamic instability and the mechanism of flutter. 496, U.S. Advisory Committee for Aeronautics, Langley, VA, U.S.A.

[4] Klöppel, K. and Weber, G. (1963). Teilmodellversuche zur Beurteilung des aerodynamischen Verhaltens von Brücken. Der Stahlbau 4, 113-121.

[5] Frandsen, A.G. (1966). Wind stability of suspension bridges. Paper 43 of International Symposium on Suspension Bridges, Proceedings. Laboratório Nacional de Engenharia Civil, Lisboa. 
[6] Tesar, A. (1978). Aeroelastic Response of Transporter Shell Bridges in Smooth Air Flow. Trondheim: The Norwegian Institute of Technology, Tapir Publisher.

[7] Tesar, A. (1988). Transfer Matrix Method. Dordrecht, Boston, London: KLUWER Academic Publishers.

[8] Tesar, A. and Svolik, J. (1993). Wave distribution in fibre members subjected to kinematic forcing. Int. Journal for Communication in Numerical Mechanics, 9, 156-164.

[9] Juhásová, E., Motlík I., and Vrabec, M. (1998). Some experiences with calibration and modeling in wind tunnel of ICA SAS. Building Research Journal, 46, 47-69.

[10] STN EN 1991-1-4 Eurocode 1. Structural loads. Part 1.4. General loads. Wind loads.

[11] Tesar, A. and Tvrda, K. (2006). Energy approach for analysis of nonlinear time response. Building Research Journal, Vol. 54, Nr. 2, 101-122.

[12] Tesar, A. and Tvrda, K. (2007). Energy approach for solution of nonlinear natural vibration. Building Research Journal, Vol. 55, Nr. 1-2, 71-84.

[13] Hautoy, C. (1990). Simulation des proprietes dynamiques du vent. Souflerie a couche limite du C.S.T.B., Nantes, France.

[14] Moonen, P., Blocken, B. and Carmeliet, J. (2007). Indicators for the evaluation of wind tunnel test section flow quality and application to a numerical closed circuit wind tunnel. J.W.E.I.A., (95), 1289-1314.

[15] Teleman, E.C., Silion, R., Axinte, E. and Pescaru, R. (2008). Turbulence scales simulations in atmospheric boundary layer wind tunnels. Bulletinul Institutului Polytehnic din Iasi, Publicat de Universitatea Tehnica "Gheorghe Asachi” din Iasi, Tomul LIV (LVIII), Fasc. 2, 7-14

[16] Tesar, A. (2011). Aeroelastic Assessment of Elements of Photovoltaic Power Plants. Technical Report for RAAB VILLANZSZERELÖ KFT., CSÖRGÖFA SOR 6, 9027 GYÖR, Institute for Construction and Architecture, Slovak Academy of Sciences, Bratislava. 